\title{
STIMULASI AYAH PADA PERKEMBANGAN PSIKOSEKSUAL BAYI \\ DENGAN PENDEKATAN KONSEP MODEL KEPERAWATAN \\ MERCER DI POSYANDU AYAH DUSUN PETENGAN DESA \\ TAMBAK REJO KECAMATAN JOMBANG KABUPATEN JOMBANG
}

\section{Father's Stimulation To The Development of Baby's Sexual Psych With The Approach Of Mercer's Nursing Model Concept At Integrated Health Center For Father at Petengan Jombang District}

\author{
Ayu Widy Lestari, Ririn Probowati, Anja Hesnia Kholis \\ STIKES Pemkab Jombang \\ E-mail : ayuwidylestari@gmail.com
}

\begin{abstract}
ABSTRAK
Perkembangan psikoseksual pada bayi perlu adanya bantuan dari orang tua dilingkungan tempat tinggalnya, apabila bayi kurang stimulasi dari kedua orang tua maka akan mengakibatkan penyimpangan perkembangan psikoseksualnya. Apabila pada fase oral tidak terpenuhi maka bayi akan mempunyai kebiasaan seperti menggigit kuku, menghisap jari. Tujuan penelitian mengetahui adanya stimulasi ayah pada perkembangan psikoseksual bayi.

Desain penelitian menggunakan analitik korelasional dengan pendekatan retrospektif. Populasi seluruh bayi yang berumur 0 sampai 12 bulan sebanyak 60 orang. Besar sampel 30 responden dengan menggunakan Simple Random Sampling. Variabel independen stimulasi ayah, variabel dependen perkembangan psikoseksual bayi. Pengumpulan data kuesioner dan observasi. Dilakukan tanggal 14-16 Mei \& 20-21 Mei 2017 menggunakan uji statistik Chi- square, pengumpulan data dengan $\alpha 0,05$.

Hasil penelitian Stimulasi yang dilakukan oleh ayah sebagian besar 16 orang $(53,3 \%)$ memiliki stimulasi negatif tentang perkembangan psikoseksual bayinya. Perkembangan psikoseksual bayi sebagian besar (70,0\%) memiliki perkembangan psikoseksual tercapai. Hasil uji statistik Chi- squaredidapat $\rho$ value $0,079 \geq \alpha$. Artinya tidak ada hubungan stimulasi ayah pada perkembangan psikoseksual bayi .

Ayah yang memiliki stimulasi negatif dalam menerapkan perkembangan psikoseksual pada fase oral hampir seluruhnya tercapai, dikarenakan stimulasi bisa di dapatkan tidak hanya diberikan oleh ayah tetapi juga bisa diberikan oleh ibu atau keluarga terdekat bayi.Diharapkan ayah bisa lebih sering memberikan stimulasi pada setiap kesempatan serta bisa memanfaatkan waktu untuk menstimulasi agar bayi bisa berkembang secara optimal.
\end{abstract}

Kata Kunci : Stimulasi ayah, Perkembangan psikoseksual bayi

\begin{abstract}
Stimulation is an Activity of stimulating the basic ability of children in order to develop optimally. Every child needs to get regular stimulation early and continuously at every opportunity. The Development of stimulation is done by mothers, fathers, baby sitters, other family members and community groups in the surrounding environment. This research aimed to determine father's stimulation to the development of baby's sexual psycho with the approach of Mercer's Nursing Model Concept at Integrated Health Center ( Posyandu ) For Father

This research design was correlation analytic with retrospective approach with all population for all babies as old as $0-12$ months at Posyandu for father. at Petengan Sub Village , Tambak Rejo Village, Jombang Sub District, in Jombang District as manay as 60 people . the
\end{abstract}


total of samples was 30 respondents that were taken by using Simple Random sampling, independent variable was father's stimulation and dependent variable was the development of baby's sexual psycho. Data collection for father 's stimulation used questionnaire and the development of baby's sexual psycho used observation. This research was done on May $14^{\text {th }}$, $15^{\text {th }}, 16^{\text {th }}$ and on May $20^{\text {th }}, 21^{\text {st }} 2017$. It was analyzed by the statistical test of Chi - Square.

This result of research showed that stimulation that was done by father, the most respondents had negative stimulation about the development of baby's sexual psycho as many as $16(53,3 \%)$ the development of baby's sexual psycho showed that the most respondents had sexual psycho development that is achieved as many as 21 people $(70,0 \%)$. The result of ChiSquare statistical test was obtained $\rho$ value 0,079 was bigger than $\alpha 0,05$, thus $\mathrm{H} 0$ was accepted, $\mathrm{H} 1$ was rejected

Based on this research above was known that there wasn't the correlation of father's stimulation to the development of baby's sexual psycho at Integrated Health Center/Posyandu For Father, Petengan Sub Village , Tambak Rejo Village , Jombang Sub District, in Jombang District. Father is advised to stimulate his baby 's sexual psycho regularly.

Key words : Father's stimulation, The development of baby's sexual psycho

\section{PENDAHULUAN}

Setiap anggota mempunyai peran masing-masing. Peran ibu yaitu sebagai pengurus rumah tangga, pengasuh, pendidik anak-anak, pelindung keluarga dan juga sebagai pencari nafkah tambahan keluarga. Sedangkan peran ayah yaitu sebagai pemimpin keluarga, pencari nafkah, pendidik, pelindung, pengayom, dan pemberi rasa aman kepada anggota keluarga (Zaidin, 2009).

Stimulasi ayah pada perkembangn psikoseksual bayi dengan konsep teori Mercer: Model Maternal Role Attainment Becoming a Father mengembangkan salah satu model konseptual keperawatan yang mendasari keperawatan anak yaitu Model Maternal Role Attainment Becoming a Father. Fokus utama dari teori ini adalah gambaran proses perkembangan bayi dan proses menjadi peran ayah untuk bayinya. Faktor perkembangan bayi dapat dipengaruhi oleh interaksi ayah yaitu salah satunya saat ayah mendukung bayi untuk belajar dalam perkembangan motorik kasarnya. Proses pencapaian peran ayah dipengaruhi oleh interaksi sentral yang tinggal dalam satu lingkungan (Alligod \& Ann Marriner, 2006).
Perkembangan psikoseksual pada bayi perlu adanya bantuan dari orang tua dilingkungan tempat tinggalnya, apabila bayi kurang stimulus dari kedua orang tua maka akan mengakibatkan penyimbangan perkembangan psikoseksualnya. (Putra, 2014).

Berdasarkan Studi pendahuluan di Jombang terdapat tujuh posyandu, diantaranya ada di Desa Kabuh, Ploso Desa Mbawangan, Ploso Desa Rejoagung, Kesamben, Tembelang, Tambak Rejo, Peterongan. Berdasarkan studi pendahuluan yang dilakukan pada tanggal 6 Februari 2017 bahwa posyandu ayah yang berjalan aktif ada di Dusun Petengan, Desa Tambak Rejo, Kecamatan Jombang.

Berdasarkan uraian latar belakang diatas, maka peran orang tua sangat berpengaruh pada perkembangan psikoseksual bayi, peran orang tua tidak boleh lepas dari bayi saat bayi mulai dalam perkembangan. Peran ayah bisa sangat berpengaruh terhadap perkembangan psikoseksual bayi karena bayi biasanya lebih senang dan menikmati jika diasuh oleh ayah. Selanjutnya, peneliti tertarik mengambil judul "Stimulasi ayah pada perkembangan psikoseksual bayi dengan pendekatan konsep model keperawatan Mercer di Posyandu Ayah Dusun 
Petengan Desa Tambak Rejo Kecamatan Jombang Kabupaten Jombang”.

\section{METODE PENELITIAN}

Desain penelitian menggunakan rancangan korelasional. Penelitian ini menggunakan pendekatan metode Retrospektif.

Populasi seluruh bayi yang berumur 0 sampai 12 bulan sebanyak 60 orang. Besar sampel 30 responden dengan menggunakan Simple Random Sampling.

Pengumpulan data kuesioner dan observasi. Dilakukan tanggal 14-16 Mei \& 20-21 Mei 2017 menggunakan uji statistik Chi- square, pengumpulan data dengan $\alpha 0,05$.
HASIL

Sebagian besar $(53,3 \%)$ responden memiliki stimulasi negatif tentang perkembangan psikoseksual bayinya. Perkembangan psikoseksual bayi menunjukkansebagian besar (70,0\%)respondenmemiliki perkembangan psikoseksual tercapai. Hasil uji statistik Chi- squaredidapat $\rho$ value $0,079 \geq \alpha$. Artinya tidak ada hubungan stimulasi ayah pada perkembangan psikoseksual bayi .

Hasil penelitian dikelompokkan menjadi dua bagian, yaitu data umum dan data khusus yang disajikan dalam bentuk tabel sebagai berikut :

Tabel 1 Karakteristik data umum responden ayah

\begin{tabular}{clcc}
\hline No. & \multicolumn{1}{c}{ Data Umum } & frekuensi & Presentase $(\%)$ \\
\hline 1 & Usia & & \\
& 17-25 Tahun & 1 & 3,3 \\
& 26-35 Tahun & 5 & 16,7 \\
& 36-45 Tahun & 24 & 80,0 \\
2 & & \\
& Pendidikan & 4 & 13,3 \\
& SD/MI & 4 & 13,3 \\
& SMP/MTs & 14 & 46,7 \\
& SMU/SMK/MA/SLTA & 8 & 26,7 \\
& Perguruan tinggi & & \\
Pekerjaan & 2 & 6,7 \\
& Buruh tani & 1 & 3,3 \\
& Petani & 10 & 33,3 \\
& Karyawan & 13 & 43,3 \\
& Pedagang & 3 & 10,0 \\
& PNS & 1 & 3,3 \\
& POLRI & 0 & 6,7 \\
& TNI & 0 & 3,3
\end{tabular}

Sumber data primer 2017

Tabel 2 Tabulasi silang antara stimulasi ayah dengan perkembangan

\begin{tabular}{|c|c|c|c|c|c|c|}
\hline \multirow{3}{*}{ Stimulasi Ayah } & \multicolumn{4}{|c|}{ Perkembangan psikoseksual bayi } & \multirow{2}{*}{\multicolumn{2}{|c|}{ Total }} \\
\hline & \multicolumn{2}{|c|}{ Tercapai } & \multicolumn{2}{|c|}{ Tidak tercapai } & & \\
\hline & $\mathbf{f}$ & $\%$ & f & $\%$ & $\mathbf{f}$ & $\%$ \\
\hline Positif & 12 & 85,7 & 2 & 14,3 & 14 & 100 \\
\hline Negatif & 9 & 56,2 & 7 & 43,8 & 16 & 100 \\
\hline Total & 21 & 70,0 & 9 & 30,0 & 30 & 100 \\
\hline
\end{tabular}

Sumber data primer 2017 


\section{PEMBAHASAN}

\section{Stimulasi Ayah}

Tabel 2 menunjukkan bahwa sebagian besar responden memiliki stimulasi negatif tentang perkembangan psikoseksual pada bayinya.

Selain faktor kelainan di dalam tubuh si anak, keterlambatan perkembangan anak juga bisa disebabkan oleh sedikitnya rangsangan yang diterima si kecil baik oleh pengasuh maupun orangtua. Orang tua menganggap bahwa perkembangan anak dapat tercapai dengan sendirinya tanpa adanya stimulasi (Hidayati, 2011).

Berdasarkan peneliti hal ini tidak terdapat kesesuaian dengan hasil penelitian bahwa ayah yang memiliki stimulasi negatif tidak dapat menerapkan perkembangan psikoseksual bayi dikarenakan ayah tidak sepenuhnya mendampingi bayi saat berada dirumah sehingga tidak sepenuhnya untuk memperikan stimulasi pada setiap kesempatan yang ayah miliki. Stimulasi tidak hanya dilakukan oleh ayah saja tetapi juga bisa dilakukan oleh keluarga terdekat misalnya ibu yang sehari-hari bersama dan mendampingi bayi.

\section{Perkembangan Psikoseksual Bayi}

Tabel 2 menunjukkan bahwa sebagian besar responden memiliki perkembangan psikoseksual tercapai.

Perkembangan secara luas menunjukan pada keseluruhan proses perubahan dari potensi yang dimiliki individu dan tampil dalam kualitas kemampuan, sifat dan ciri-ciri yang baru. Faktor-faktor yang mempengaruhi perkembangan diantaranya: Faktor hereditas (warisan sejak lahir atau bawaan), Faktor lingkungan, Kematangan fungsi- fungsi organis dan psikis, Aktifitas anak sebagai subyek bebas yang berkemauan (kemampuan seleksi, bisa menolak atau menyetujui, punya emosi, serta usaha membangun diri sendiri) (Sarlito \& Sarwono, 1991).

Sebagian besar perkembangan terjadi akibat dari kematangan dan pengalaman sebagai hasil belajar, namun masih dapat dioptimalkan dengan pemberian rangsangan-rangsangan atau stimulasi perkembangan. Perkembangan psikoseksual pada fase oral dikatakan tercapai jika bayi sudah bisa menghisap (ASI), mengunyah (makanan MP-ASI), menggigit (MP-ASI) dan jika perkembangan psikoseksual tidak tercapai maka bayi akan mempunyai kebiasaan menghisap jempol, menggigit kuku.

\section{Hubungan Stimulasi Ayah pada Perkembangan Psikoseksual Bayi.}

Continuity Correction $\rho$ value yang diperoleh dapat dilihat pada Person Chisquare yaitu $\mathrm{p}$ value $=0,079$, dimana nilai $\rho$ value $>\alpha(0,05)$. Dari hasil hitung $\rho$ value 0,079 lebih besar dari $\alpha 0,05$ maka $\mathrm{H}_{1}$ ditolak. sehingga dapat disimpulkan bahwa tidak ada hubungan stimulasi ayah dengan perkembangan psikoseksual bayi dengan pendekatan konsep model keperawatan Mercer di Posyandu Ayah Dusun Petengan Desa Tambak Rejo Kecamatan Jombang Kabupaten Jombang.

Menurut konsep model Mercer perkembangan bayi dapat dipengaruhi oleh Role Attainment ibu dalam pemberian pengasuhan pada perkembangan bayi. Perkembangan bayi juga dapat dipengaruhi oleh faktor lain, faktor bayi sendiri dan faktor ibu (Alligod \& Ann Marriner, 2006). Salahsatu dari perkembangan bayi adalah perkembangan psikoseksual bayi yang bisa dipengaruhi oleh faktor ayah yaitu melalui stimulasi ayah, selain itu juga dapat melalui dukungan ayah dan interaksi ayah (Probowati, 2016). Stimulasi merupakan kegiatan merangsang kemampuan dasar anak agar anak tumbuh dan berkembang secara optimal.

Perkembangan anak bisa tercapai dan tidak tercapai tidak hanya dipengaruhi oleh faktor dari stimulasi ayah tetapi juga bisa dipengaruhi oleh faktor lainnya yaitu dalam bentuk dukungan. Bayi juga dapat perkembang jika dapat mendapat dukungan lebih dari 
ayah maupun dari ibu dan keluarga terdekat.

Menurut peneliti, penelitian ini tidak terdapat kesesuaian dengan fakta diatas dimana ayah yang memiliki stimulasi negatif dalam menerapkan perkembangan psikoseksual pada fase oral hampir seluruhnya tercapai. Dikarenakan stimulasi bisa di dapatkan tidak hanya diberikan oleh ayah saja tetapi juga bisa diberikan oleh ibu atau keluarga terdekat bayi. Dengan demikian jika perkembangan psikoseksual bayi bisa tercapai.

\section{KESIMPULAN}

Berdasarkn data yang telah disajikan dalam bab sebelumnya maka dapat diambil kesimpulan sebagai berikut:

1. Sebagian besar $(53,3 \%)$ respondenmemiliki stimulasi negatif tentang perkembangan psikoseksual bayinya.

2.Perkembangan psikoseksual bayi menunjukkanbahwasebagian besar (70,0\%)respondenmemiliki perkembangan psikoseksual tercapai.

3.Tidak ada hubungan antara stimulasi ayah pada perkembangan psikoseksual bayi dengan konsep model keperawatan mercer di posyandu ayah Dusun Petengan Desa Tambak Rejo Kecamatan Jombang Kabupaten Jombang ditunjukkan dengan nilai $\rho$ value 0,079 lebih besar dari $\alpha 0,05$ artinya tidak ada hubungan antara variabel independen dan dependen.

\section{SARAN}

a. Bagi ayah

Ayah diharapkan lebih dekat dengan bayi pada setiap kesempatan, karena peran ayah juga penting dalam pemberian stimulasi bayi sejak usia dini.

b. Petugas kesehatan Diharapkan adanya sosialisasi pada kegiatan posyandu balita, agar ayah mempunyai peran penting dalam menstimulasi bayi terhadap perkembangannya.

c. Bagi peneliti selanjutnya

Berdasarkan jumlah sampel yang sedikit, peneliti diharapkan menambah atau meningkatkan jumlah populasi dansampel yang diteliti.

\section{DAFTAR PUSTAKA}

Alligod \& Ann Marriner. 2006. Nursing Theorists And Their Work Seventh Edition. Amerika: Mosby Elsevier.

Hidayati, Farida, dkk. 2011. Peran Ayah Dalam Pengasuhan Anak.http://journal.unusa.ac.id/ind ex.php. Diakses pada tanggal 18/12/2016.

Probowati, Ririn. 2016. Model Keperawatan Role Attainment Ibu Bekerja Dengan Pendekatan SelfEfficacy Dalam Kompetensi Stimulasi Pertumbuhan Dan Perkembangan Bayi. Disertasi. http://repository.unair.ac.id/33238 /

Putra D S, dkk. 2014. Keperawatan Anak \& Tumbuh Kembang. Jakarta Selatan: Salemba Medika.

Sarlito \& Sarwono. 1991.Keperawatan Anak \& Tumbuh Kembang. Jakarta Selatan: S

Vera. 2006. Nursing Theorists And Their Work Seventh Edition. Amerika: Mosby Elsevier.

Zaidin. 2009. Pengantar keperawatan keluarga. Jakarta: Buku Kedokteran EGC. 